\title{
RESPIRATORY SYMPTOMS OF EXPOSURE TO SUBSTANCES IN THE WORKPLACE AMONG DENTAL LABORATORY TECHNICIANS
}

\author{
Iliyana Stoeva
}

Medical University, Plovdiv, Bulgaria

Department of Diagnostic Imaging, Dental Allergology and Physiotherapy

\begin{abstract}
Background: As dental technicians are exposed to a variety of airborne chemicals that can act as irritants and sensitizers, and may give rise to work-related respiratory symptoms, the aim of this study was to estimate the prevalence of respiratory symptoms of exposure to substances in the workplace and associated risk factors in dental laboratory technicians. Material and Methods: A cross-sectional study was performed among 539 dental technicians in the Plovdiv region using a self-report questionnaire. A multiple logistic regression analysis was performed in order to investigate the relationship between sex, work experience, daily exposure to chemicals from the dental environment, and a history of atopic disorder with work-related respiratory symptoms. Results: A total of 539 dental technicians completed the questionnaire. The prevalence of self-reported work-related respiratory symptoms was $26.2 \%$. Based on logistic regression, the most significant factors associated with work-related respiratory symptoms were daily exposure of $>8 \mathrm{~h}(\mathrm{OR}=5.83$, 95\% CI: 1.96-17.34) and the lack of a ventilation system ( $\mathrm{OR}=4.26,95 \%$ CI: 2.39-7.58). Dental technicians with work experience of $<5$ years more often reported work-related respiratory symptoms $(\mathrm{OR}=1.83,95 \% \mathrm{CI}$ : $1.14-3.44)$ compared to those with longterm exposure of $>20$ years. A personal history of asthma $(\mathrm{OR}=3.74,95 \% \mathrm{CI}$ : $1.39-10.07)$, allergic rhinoconjunctivitis $(\mathrm{OR}=2.10$, $95 \%$ CI: $1.29-3.41)$ and atopic dermatitis $(\mathrm{OR}=2.32,95 \% \mathrm{CI}: 1.23-4.38)$ was also associated with work-related respiratory symptoms. Conclusions: The findings of this study suggest that work-related respiratory symptoms are frequent among dental technicians and occur early in their career. A more comprehensive study should be conducted throughout the country in order to estimate the prevalence, and to establish effective programs and techniques of preventing work-related respiratory symptoms in dental technicians. Med Pr. 2021;72(2):105-11
\end{abstract}

Key words: dust, respiratory symptoms, acrylic resins, daily exposure, atopic disorder, dental technicians

Corresponding author: Iliyana Stoeva, Medical University, Department of Diagnostic Imaging, Dental Allergology and Physiotherapy, Bul. Hristo Botev 3, 4002 Plovdiv, Bulgaria, e-mail: stoeva_iliana@abv.bg

Received: June 6, 2020, accepted: September 1,2020

\section{INTRODUCTION}

The environment of a dental laboratory involves exposure to multiple airborne chemical substances that act as irritants and allergens, and may cause respiratory symptoms as well as pulmonary disorders [1-3]. Dental technicians are chronically exposed to various dusts - gypsum, met$\mathrm{al}$ and acrylic dust originating from the trimming and polishing of dental alloys and acrylic dentures. These small particles are inhaled into the lungs and may lead to lung diseases such as pneumoconiosis [4-6]. Repeated aspiration of several chemical agents may lead to hypersensitive pneumonitis $[7,8]$ or asthma $[9-11]$.
Dentistry has changed significantly in the last 2 decades. Implantology has undergone a successful transformation and has permitted the use of fixed dental restorations in the posterior edentulous regions. In addition, the demand for cosmetic prostheses has risen, especially among the aging population, resulting in a less common use of removable dentures, and a wider application of bridges and crowns. In line with the innovations in prosthodontic treatment, dental laboratory work has changed. It requires new data on the effects of airborne chemicals in the environment of a modern dental laboratory, long-term effects of inhalation of respiratory irritants and allergens, the consequences for 
occupational activity, and associated factors increasing the prevalence of work-related respiratory symptoms.

The aim of this study was to investigate the prevalence of self-reported work-related respiratory symptoms among dental technicians and to assess associated factors contributing to their onset.

\section{MATERIAL AND METHODS}

This was a cross-sectional study conducted through a self-administered questionnaire sent to the dental technicians in the Plovdiv region, and implemented with the agreement and assistance of the president of the Bulgarian Dental Technicians Union. The survey used an online questionnaire which was created using Google Drive and sent by e-mail, as a link, to dental technicians. Data collection was performed in autumn 2018. The questions concerned:

- personal and professional data of the dental technicians (age, sex, years of laboratory practice, working hours/day categorized as $<6 \mathrm{~h}, 6-8 \mathrm{~h},>8 \mathrm{~h}$ );

qualification (categorized as dental technicians occupied with removable prosthesis and with fixed prosthesis);

the use of protective equipment (masks and gloves), and the type of protective gloves;

allergic disorders such as asthma, hay fever, or eczema. A history of atopic dermatitis (infant eczema or eczema on knee and elbow flexures), allergic rhinoconjunctivitis, or asthma were accepted as signs of atopy;

smoking;

work-related respiratory symptoms. The participants were asked whether they had observed any work-related respiratory reactions. In the case of a positive response, the online questionnaire generated additional questions specifying the time of the onset of symptoms, the characteristics of symptoms, (cough, hoarseness, dyspnea, wheezing, nasal and eye symptoms, pharyngitis, and others), the evolution of symptoms from the onset to the present, suspected causes of work-related respiratory symptoms, and career consequences.

Prior to the final study, a pilot study was conducted among dental staff at the Faculty of Dental Medicine in Plovdiv. In total, 84 members of different subgroups of dental staff (47 dentists, 28 dental nurses, and 9 dental technicians) participated in that study, in order to assess how clear and comprehensible the wording was. The questionnaire was built on statements with tick-box categories to facilitate its completion, some of them with an option to add another response. In order to assess the real prevalence of work-related respiratory symptoms and to reduce the possibility of bias, the participants were additionally asked whether these symptoms had decreased or disappeared during long holidays ( $\geq 3$ weeks). Only those with a positive reply were considered as having work-related symptoms. The pilot study findings revealed no need to change the proposed questions.

The study was approved by the Ethics Committee of the Medical University, Plovdiv, No. 08/2018.

The information from the digital questionnaire was exported to a database file. A statistical analysis was carried out with SPSS, version 18.0. Descriptive statistics were used to evaluate the prevalence of various exposures and symptoms. Differences between dentists with or without self-reported work-related respiratory symptoms were investigated using cross-tabulations and $\chi^{2}$ tests. A univariate logistic regression analysis was used to examine the associations between the studied factors and work-related respiratory symptoms. The significant variables $(\mathrm{p}<0.05)$ were entered into a multiple logistic regression analysis, which was built by backward elimination. Adjusted OR and 95\% CI were calculated. The goodness of fit was assessed by the Hosmer-Lemeshow test. The level of statistical significance was set at 0.05 for all calculations.

A multiple logistic regression analysis was conducted in order to investigate the relationship between sex, work experience, daily exposure to chemicals from the dental environment, and a history of allergic rhinoconjunctivitis, asthma, and atopic dermatitis (included as independent variables in the model) with work-related respiratory symptoms (included as a dependent variable).

\section{RESULTS}

Overall, 539 dental technicians participated in the study $(\mathrm{N}=304,56.4 \%$ males $)$. Their age ranged $21-65$ years with $\mathrm{M} \pm \mathrm{SD}$ of $47.3 \pm 11.0$. The mean duration of work as a dental technician was $24.8 \pm 11.5$ years (range: $1-45$ years).

A total of 141 (26.2\%) participants reported current work-related respiratory symptoms. The female dental technicians were more likely to have respiratory symptoms related to their occupation. No association was found between smoking and self-reported work-related respiratory symptoms. A higher 
Table 1. Demographic and work style characteristics of dental technicians and their association with work-related respiratory symptoms (WRRS) in September-December 2018 in the Plovdiv region, Bulgaria

\begin{tabular}{|c|c|c|c|c|}
\hline \multirow{2}{*}{ Variable } & \multicolumn{3}{|c|}{$\begin{array}{c}\text { Participants } \\
(\mathrm{N}=539)\end{array}$} & \multirow{2}{*}{$\mathrm{p}$} \\
\hline & total & $\begin{array}{l}\text { with WRRS } \\
(\mathrm{N}=141)\end{array}$ & $\begin{array}{l}\text { without WRRS } \\
\qquad(\mathrm{N}=398)\end{array}$ & \\
\hline Age [years] $(\mathrm{M} \pm \mathrm{SD})$ & $43.3 \pm 11.0$ & $46.9 \pm 11.5$ & $47.5 \pm 10.8$ & 0.549 \\
\hline Sex - women $[\mathrm{n}(\%)]$ & $235(43.6)$ & $80(56.7)$ & $155(38.9)$ & $<0.001$ \\
\hline Work experience [years] $(\mathrm{M} \pm \mathrm{SD})$ & $24.8 \pm 11.5$ & $24.0 \pm 12.0$ & $25.0 \pm 11.3$ & 0.376 \\
\hline \multicolumn{5}{|l|}{ Daily exposure $^{\star}[\mathrm{n}(\%)]$} \\
\hline$<6 \mathrm{~h}$ & $44(8.2)$ & $9(6.4)$ & $35(8.8)$ & \\
\hline $6-8 \mathrm{~h}$ & $312(57.9)$ & $68(48.2)$ & $244(61.3)$ & 0.004 \\
\hline latex & $105(64.0)$ & $35(70.0)$ & $70(61.4)$ & 0.377 \\
\hline other & $59(36.0)$ & $15(30.0)$ & $44(38.6)$ & \\
\hline mask & $291(54.0)$ & $90(63.8)$ & $201(50.5)$ & 0.008 \\
\hline
\end{tabular}

* Duration of the working day (h).

percentage of both the use of a protective mask and a prolonged working day ( $>8 \mathrm{~h} /$ day) was identified in dental technicians reporting work-related respiratory symptoms. Protective gloves were used by $30.4 \%$ of dental technicians, and no association between the use of latex gloves and work-related respiratory symptoms was found (Table 1).

Cough was the most frequently reported symptom, followed by eye symptoms (Table 2). The most common causes of respiratory reactions were attributed to materials based on acrylic resins (77.3\%), followed by plaster (43.3\%), disinfectants (23.4\%), metals (21.9\%), and ceramic powder (9.2\%). A minority of dental technicians $(2.1 \%)$ pointed out that protective gloves were the cause of their symptoms.

Most dental technicians reported no change of symptoms from the onset up to the current moment, and one-fourth reported the aggravation of symptoms (Table 3 ). Only $35.5 \%$ of dental technicians declared that these symptoms did not affect their occupational activity. Nearly half of the symptomatic dental technicians considered medical consultation, and men were more prone to visit a physician. In addition, $11.3 \%$ considered a change of their occupation due to work-related respiratory symptoms, and all of them were women.
Table 2. Work-related respiratory symptoms (WRRS) reported by dental technicians (multiple answers) in September-December 2018 in the Plovdiv region, Bulgaria

\begin{tabular}{lcc}
\hline \multirow{2}{*}{ Symptom } & \multicolumn{2}{c}{$\begin{array}{c}\text { Participants with WRRS } \\
(\mathrm{N}=141)\end{array}$} \\
\cline { 2 - 3 } & $\mathrm{n}$ & $\%$ \\
\hline Cough & 76 & 53.9 \\
Eye (runny, itchy eyes) & 71 & 50.4 \\
Dyspnea & 31 & 22.0 \\
Nasal (blocked or runny nose or sneezing) & 24 & 17.0 \\
Pharyngitis & 21 & 14.9 \\
\hline
\end{tabular}

A history of atopy defined by the presence of childhood dermatitis, allergic rhinitis and/or asthma was present in 178 (33.0\%) of the participants. Dentists with atopic constitution were more affected by work-related respiratory reactions than those without a history of atopic disease $(35.4 \%$ vs. $21.6 \%, \mathrm{p}<0.001$, respectively).

According to the logistic regression analysis, daily exposure of $>8 \mathrm{~h}$ and the lack of a ventilation system were the most significant risk factors for work-related respiratory symptoms among dentists (Table 4). The risk was higher at the beginning of dental laboratory practice $(\mathrm{OR}=1.83,95 \% \mathrm{CI}: 1.14-3.44$ for work experience 
Table 3. Evolution of work-related respiratory symptoms (WRRS) and consequences for occupational activity in September-December 2018 in the Plovdiv region, Bulgaria

\begin{tabular}{|c|c|c|c|c|}
\hline Variable & \multicolumn{3}{|c|}{$\begin{array}{c}\text { Participants } \\
(\mathrm{N}=141) \\
{[\mathrm{n}(\%)]}\end{array}$} & $\mathrm{p}$ \\
\hline \multicolumn{5}{|l|}{ Evolution of work-related respiratory symptoms from the onset up to the present } \\
\hline symptoms remain the same & $90(63.8)$ & $40(65.6)$ & $51(63.8)$ & $<0.001$ \\
\hline symptoms tend to decline & $15(10.6)$ & - & $14(17.5)$ & \\
\hline \multicolumn{5}{|l|}{ Consequences for occupational activity } \\
\hline these symptoms do not affect my work & $50(35.5)$ & $10(16.4)$ & $40(50.0)$ & $<0.001$ \\
\hline I am thinking of consulting a physician & $66(46.8)$ & $51(83.6)$ & $15(18.8)$ & \\
\hline
\end{tabular}

* $\mathrm{p}$-value obtained with the $\chi^{2}$ test, comparing the sexes.

Table 4. Association between work-related respiratory symptoms (WRRS) and potential risk factors, using a multiple logistic regression analysis, in September-December 2018 in the Plovdiv region, Bulgaria

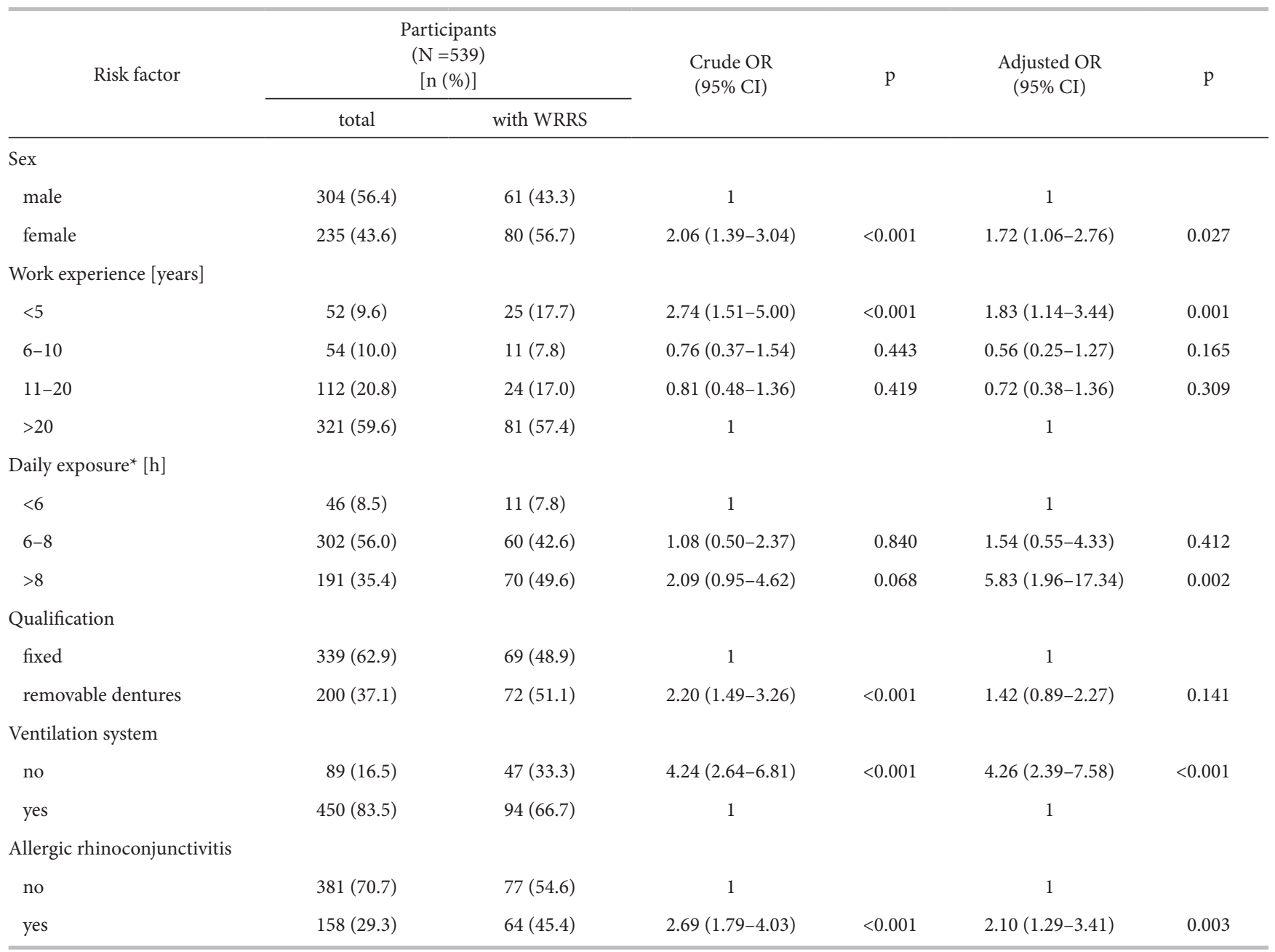


Table 4. Association between work-related respiratory symptoms (WRRS) and potential risk factors, using a multiple logistic regression analysis, in September-December 2018 in the Plovdiv region, Bulgaria - cont.

\begin{tabular}{|c|c|c|c|c|c|c|}
\hline \multirow[t]{2}{*}{ Risk factor } & \multicolumn{2}{|c|}{$\begin{array}{l}\text { Participants } \\
(\mathrm{N}=539) \\
{[\mathrm{n}(\%)]}\end{array}$} & \multirow[t]{2}{*}{$\begin{array}{c}\text { Crude OR } \\
(95 \% \text { CI })\end{array}$} & \multirow[t]{2}{*}{$\mathrm{p}$} & \multirow[t]{2}{*}{$\begin{array}{c}\text { Adjusted OR } \\
\quad(95 \% \mathrm{CI})\end{array}$} & \multirow[t]{2}{*}{$\mathrm{p}$} \\
\hline & total & with WRRS & & & & \\
\hline \multicolumn{7}{|l|}{ Asthma } \\
\hline no & $502(93.1)$ & $121(85.8)$ & 1 & & 1 & \\
\hline \multicolumn{7}{|l|}{ Atopic dermatitis } \\
\hline no & $478(88.7)$ & $117(83.0)$ & 1 & & 1 & \\
\hline yes & $61(11.3)$ & $24(17.0)$ & $2.00(1.15-3.48)$ & 0.014 & $2.32(1.23-4.38)$ & 0.009 \\
\hline
\end{tabular}

${ }^{*}$ Daily exposure to chemicals from the dental laboratory environment (duration of the working day).

of $<5$ years). A history of asthma ( $\mathrm{OR}=3.74,95 \% \mathrm{CI}$ : $1.39-10.07)$ was more strongly associated with work-related respiratory symptoms than the other atopic conditions such as allergic rhinoconjunctivitis $(\mathrm{OR}=2.10$, 95\% CI: $1.29-3.41)$ and dermatitis $(\mathrm{OR}=2.32,95 \% \mathrm{CI}$ : $1.23-4.38)$.

\section{DISCUSSION}

In the present study, the prevalence of self-reported work-related respiratory symptoms among dental technicians in the Plovdiv region and associated factors were investigated. Most of the studies addressing the impact of airborne hazardous substances and dust on dental technicians are focused on pneumoconiosis, and a few studies present data on the prevalence of work-related respiratory symptoms. This study revealed that $26.2 \%$ of the inquired dental technicians reported respiratory symptoms related to airborne irritants and allergens from the environment of a dental laboratory. These findings are similar to data from Sweden which indicated that $29 \%$ of dental technicians developed work-related airway symptoms [12]. Based on these findings, dental technicians pointed out materials based on acrylic resins as the major cause for adverse respiratory reactions.

Polymethyl methacrylate resins continue to be largely used in dental laboratory work, not only for the fabrication of dentures but also for removable orthodontic appliances. Laboratory composites used for inlays and overlays are also based on acrylic resins. Methacrylates are well-known contact allergens [13], but they can also induce respiratory hypersensitivity [14] as they evaporate at room temperature. The hypersensitivity of the upper airways and occupational asthma have been reported from substances containing methacrylates $[10,11,15,16]$. In addition, according to the logistic regression analysis, dental technicians occupied with removable dentures are more likely to develop respiratory symptoms (Table 4). Most of the materials for dentures are based on acrylic resins, and dental technicians are exposed to unpolymerized acrylic monomers.

Notably, 23.4\% of dental technicians suspected disinfectants to be the cause of their respiratory symptoms. The dental profession is advised to adhere strictly to recommended infection control strategies in the healthcare settings. Adverse reactions to disinfectants are more likely to be reported by clinical dental staff. Spray disinfectants are also used by dental laboratory technicians for dental impressions and stone casts, in order to avoid the cross-contamination resulting in exposure to additional hazardous substances besides plaster, metal and acrylic dust. Disinfectants contain mainly glutaraldehyde and quaternary ammonium compounds such as benzalkonium chloride which are known for their strong irritant and sensitizing effects on the respiratory tract, eyes, and skin [17-19].

Surprisingly, a higher prevalence of respiratory symptoms was reported by dentists wearing protective masks (Table 1). Face masks have a capacity for reducing the inhaled dust by about $70-95 \%$ based on weight reduction although small particles may still pass the mask, thus representing a potential health risk [20]. One possible explanation for the increased use of face masks in symptomatic dental technicians are the pre-existing respiratory symptoms that make them more likely to use masks in order to restrict the exposure to airborne hazardous substances, and thus to reduce the existing 
symptoms. However, this was a cross-sectional study limiting the possibility to claim causality and some speculation was possible.

Other strategies for minimizing the effects of occupational hazards are ventilation systems capable of keeping the dust values within acceptable levels in the workplace. The majority of the inquired dental technicians (83.5\%) worked in dental laboratories with installed ventilation systems. According to the regression analysis, the lack of aspiration increased the risk of work-related respiratory symptoms by more than 4 times. Other factors should be taken into consideration when assessing the risk of respiratory symptoms related to the occupational environment. The logistic regression analysis revealed that the risk of work-related respiratory symptoms increased significantly in dental technicians with $>8 \mathrm{~h}$ of daily exposure to airborne hazards in the workplace, compared to those with a shorter working day $(<6 \mathrm{~h})$.

Obviously, the role of working (exposure) time is important for the onset of respiratory symptoms, which may occur early in one's career (Table 4). In contrast to the study by Rabi et al. [21] where the prolonged exposure to dental manufacture ( $>15$ years) was associated with an increased respiratory morbidity, in this study a higher prevalence of work-related respiratory symptoms was reported by dental technicians with work experience of $<5$ years compared to those with work experience of $>20$ years. One possible explanation is that the affected individuals were more prone to participate in a questionnaire study concerning the health problem, and due to the small number of dental technicians with work experience of $<5$ years, some bias as regards an uneven distribution of work-related respiratory symptoms between different groups may be present. On the other hand, $11.3 \%$ of the inquired symptomatic dental technicians considered changing their occupation due to the respiratory symptoms (Table 3), so it was possible that there were some early retired individuals who did not participate in the study.

The logistic regression analysis showed that dental technicians with atopic disorder were more susceptible to the harmful effects of airborne substances in the dental laboratory on respiratory health, with a much stronger association with a history of asthma than with allergic rhinoconjunctivitis or atopic dermatitis. This is in accordance with other studies indicating that dental staff with atopic diseases are more likely to develop respiratory symptoms when exposed to airborne irritants or allergens $[10,22]$.
This cross-sectional study presents evidence on the prevalence and determinants of work-related respiratory symptoms in dental technicians, but it has some limitations. The measurement of work-related respiratory symptoms was through self-reporting and the result may not be as accurate as for those findings supported by clinical diagnoses. Dental laboratory airborne agents may evoke non-specific immune response as well as specific immune responses, and the questionnaire investigation alone cannot determine the prevalence of true allergic reactions. The factors causing respiratory reactions were ranged only on the basis of the dentists' subjective assessments without any objective evaluation regarding the link between symptoms and exposures.

\section{CONCLUSIONS}

The results of this study suggest that work-related respiratory symptoms are common in dental technicians and occur as soon as they start their practice. The lack of protective measures, such as ventilation systems, and a prolonged working day contribute significantly to the onset of respiratory symptoms. Dental technicians should be encouraged to follow protective measures. Efforts to establish effective educational programs and techniques for preventing work-related respiratory symptoms in dental technicians are necessary.

\section{REFERENCES}

1. Borak J, Fields C, Andrews LS, Pemberton MA. Methyl methacrylate and respiratory sensitization: a critical review. Crit Rev Toxicol. 2011;41(3):230-68, https://doi.org/ 10.3109/10408444.2010.532768.

2. Alavi A, Shakiba M, Nejad AT, Massahnia S, Shiari A. Respiratory findings in dental laboratory technicians in rasht (North of Iran). Tanaffos. 2011;10(2):44-9.

3. Choudat D. Occupational lung diseases among dental technicians. Tuber Lung Dis. 1994;75(2):99-104, https://doi.org/ 10.1016/0962-8479(94)90037-X.

4. Cimrin A, Kömüs N, Karaman C, Tertemiz KC. Pneumoconiosis and work-related health complaints in Turkish dental laboratory workers. Tuberk Toraks. 2009;57(3): 282-8.

5. Kartaloglu Z, Ilvan A, Aydilek R, Cerrahoglu K, Tahaoglu K, Baloglu H, et al. Dental technician's pneumoconiosis: mineralogical analysis of two cases. Yonsei Med J. 2003;44(1): 169-73, https://doi.org/10.3349/ymj.2003.44.1.169.

6. Froudarakis ME, Voloudaki A, Bouros D, Drakonakis G, Hatzakis K, Siafakas NM. Pneumoconiosis among Cretan 
dental technicians. Respiration. 1999;66(4):338-42, https:// doi.org/10.1159/000029404.

7. Kim YH, Chung YK, Kim C, Nam ES, Kim HJ, Joo Y. A case of hypersensitivity pneumonitis with giant cells in a female dental technician. Ann Occup Environ Med. 2013;25(1):19, https://doi.org/10.1186/2052-4374-25-19.

8. Scherpereel A, Tillie-Leblond I, Pommier de Santi P, Tonnel AB. Exposure to methyl methacrylate and hypersensitivity pneumonitis in dental technicians. Allergy 2004;59(8):890-2, https://doi.org/10.1111/j.1398-9995.2004. 00511.x.

9. Malo JL, Chan-Yeung M. Agents causing occupational asthma. J Allergy Clin Immunol. 2009;123(3):545-50, https://doi.org/10.1016/j.jaci.2008.09.010.

10. Savonius B, Keskinen H, Tuppurainen M, Kanerva L. Occupational respiratory disease caused by acrylates. Clin Exp Allergy. 1993;23(5):416-24, https://doi.org/10.1111/ j.1365-2222.1993.tb00348.x.

11. Losewicz S, Davison AG, Hopkirk A. Occupational asthma due to methyl methacrylate and cyanoacrylates. Thorax 1984;39:712-3, https://doi.org/10.1136/thx. 40.11.836.

12. Jacobsen N, Derand T, Hensten-Pettersen A. Profile of work-related health complaints among Swedish dental laboratory technicians. Community Dent Oral Epidemiol. 1996;24(2):138-44, https://doi.org/10.1111/ j.1600-0528.1996.tb00831.x.

13. Kanerva L, Estlander T, Jolanki R. Occupational skin allergy in the dental profession. Dermatol Clin 1994;12(3): 517-32

14. Piirilä P, Kanerva L, Keskinen H, Estlander T, Hytönen M, Tuppurainen $\mathrm{M}$, et al. Occupational respiratory hypersensitivity caused by preparations containing acrylates in dental personnel. Clin Exp Allergy. 1998;28(11):1404-11, https://doi.org/10.1046/j.1365-2222.1998.00400.x.

15. Kanerva, L, Estlander T, Jolanki R, Pekkarinen E. Occupational pharyngitis associated with allergic patch test reactions from acrylics. Allergy 1992;47(5):571-3.

16. Estlander T, Kanerva L, Kari O, Jolanki R, Mölsä K. Occupational conjunctivitis associated with type IV allergy to methacrylates. Allergy 1996;51(1):56-9, https://doi. org/10.1111/j.1398-9995.1996.tb04551.x.

17. Curran AD, Burge PS, Wiley K. Clinical and immunologic evaluation of workers exposed to glutaraldehyde. Allergy 1996;51(11):826-32, https://doi.org/10.1111/ j.1398-9995.1996.tb00029.x.

18. Di Stefano F, Siriruttanapruk S, McCoach J, Burge PS. Glutaraldehyde: an occupational hazard in the hospital setting. Allergy 1999;54(10):1105-9, https://doi.org/ 10.1034/j.1398-9995.1999.00239.x.

19. Anderson SE, Shane H, Long C, Lukomska E, Meade BJ, Marshall NB. Evaluation of the irritancy and hypersensitivity potential following topical application of didecyldimethylammonium chloride. J Immunotoxicol. 2016;13(4): 557-66, https://doi.org/10.3109/1547691X.2016.1140854.

20. Brune D, Beltesbrekke H. Dust in dental laboratories. Part III: Efficiency of ventilation systems and face masks. J Prosthet Dent. 1980;44(2):211-5.

21. Radi S, Dalphin JC, Manzoni P, Pernet D, Leboube MP, Viel JF. Respiratory morbidity in a population of French dental technicians. Occup Environ Med. 2002;59(6):398404, https://doi.org/10.1136/oem.59.6.398.

22. Jaakkola M, Leino T, Tammilehto L, Ylostalo P, Kuosma E, Alanko K. Respiratory effects of exposure to methacrylates among dental assistants. Allergy 2007;62(6):648-54, https://doi.org/10.1111/j.1398-9995.2007.01379.x.

This work is available in Open Access model and licensed under a Creative Commons Attribution-NonCommercial 3.0 Poland License - http://creativecommons.org/licenses/by-nc/3.0/pl/deed.en. 